\title{
Assessment of musculoskeltal system pain complaints reported by forestry workers
}

\author{
Piotr Choina ${ }^{1, A-C}$, Leszek Solecki²,A-F, Małgorzata Goździewska',F, Agnieszka Buczaj ${ }^{3, A-B, F}$ \\ ${ }^{1}$ Institute of Rural Health, Lublin, Poland \\ 2 Pope John Paul II State School of Higher Education, Chair of Health, Biała Podlaska, Poland \\ ${ }^{3}$ University of Life Sciences, Lublin, Poland \\ A - Research concept and design, B - Collection and/or assembly of data, C - Data analysis and interpretation, \\ $D$ - Writing the article, E - Critical revision of the article, F - Final approval of article
}

Choina P, Solecki L, Goździewska M, Buczaj A. Assessment of musculoskeltal system pain complaints reported by forestry workers. Ann Agric Environ Med. 2018; 25(2): 338-344. doi: 10.26444/aaem/86690

\begin{abstract}
Introduction. According to the European Occupational Diseases Statistics (EODS-2005) diseases related with musculoskeletal disorders occupy the first position on the obligatory list of occupational diseases. These disorders most frequently occur in the agriculture-hunting-forestry sector in such countries as: Finland, Holland, Germany, France and Spain (data: EU-OSHA). Materials and method. The study included a selected group of males - 414 forestry workers, employees of the State Forests, aged 25-65, mean age 48 . The control group were 119 office workers aged $23-64$, mean age 45.8 . The basic research instrument was a questionnaire designed by specialists concerning pain complaints occurring in 7 areas of the motor system: neck, arms, upper and lower back, hips, knees and feet.

Results. The results of the survey showed that in the selected group of forestry workers, among 7 investigated areas of the motor system, the most frequently reported pain complaints involved the lower part of the spine ( 272 persons, $65.7 \%$ of the total number of respondents). In the control group such pain complaints occurred in $55.5 \%$ (66) of office workers ( $p=0.04$ ). Forestry workers most often described this pain as permanent, radiating to the leg, or as an acute pain. According to the frequency of reporting pain, the area of the knees was placed on the second position (214 foresters; $51.7 \%$ ).

Conclusions. The work of a forester which consist, among other things, in relocation on foot or by vehicle over long distances along an uneven terrain and in various weather conditions, is a risk factor of the occurrence of musculosceletal disorders concerning the low back and knees.
\end{abstract}

Key words

pain complaints, forestry workers, motor system, low back, knees

\section{INTRODUCTION}

Musculoskeletal disorders (MSD) are the most frequent diseases related with the occupation performed, registered by the European Union, and occurring in all sectors and professions [1]. According to the obligatory list of diseases developed by the European Occupational Diseases Statistics (EODS-2005), the percentage of diseases related to musculoskeletal disorders is the highest (38.1\%) [2], followed by neurological diseases (20.9\%), and respiratory system disorders (14.3\%). In recent years, a downward tendency has been observed in the occurrence of musculoskeletal diseases. These diseases still occupy a high position (69 cases per 100,000 employees); however, they are placed on the second position following the problems of neurological nature (94 cases per 100,000 employees) [3].

According to the data by the European Survey on Working Conditions (ESWC), the most frequently reported health problems are related with the work performed (61.4\%), and concern back pain (50.5\%) and muscular pain (50.5\%) in the sectors of agriculture and fishery [4].

In turn, the frequency of occurrence (per 100,000 employees) of non-fatal diseases of the musculoskeletal system calculated by the EODS noted for the sector agriculture-hunting forestry is 20.7; and occupies the fourth position, following fishery (113.3), production facilities (73.4) and construction (54.0). Analysis of the frequency of MSD and low back pain in individual countries of the European Union (U-27) shows that these events most frequently occur in the agriculturehunting-forestry sector in Finland, Holland, Germany, France and Spain [1].

The data presented by the ESWC indicate that more than $60 \%$ of employees in the whole EU are exposed (during at least $25 \%$ of work shift) to repeated activities, approximately $45 \%$ - to painful or fatiguing positions, and 35\% - to carrying and lifting heavy loads [4]. In some professions, there may occur long-term standing or walking (more than $70 \%$ ), as well as exposure to vibration (25\%). The above-mentioned occupational risk factors are the potential cause of the development of MSD.

The information demonstrated above does not specify the MSD occurring exclusively in forestry, but most often concern the joint sector of agriculture, hunting and forestry.

International reports concerning MSD in forestry alone are scarce $[4,5,6]$. There is also a lack of studies pertaining to the evaluation of pain complaints on the part of the musculoskeletal system among Polish forestry workers. The presented article is aimed at filling the existing gap. 


\section{OBJECTIVE}

The aim of this study was assessment of the occurrence of pain complaints of the part of the musculoskeletal system reported by Polish forestry workers.

\section{MATERIALS AND METHOD}

The study covered a selected group of males - 414 forestry workers employed in the State Forests (from 16 Forestry Districts, in 8 administrative regions), aged $25-65$, mean age 48 , and duration of employment from $1-49$ years, mean 26. The mean time of work outdoors was 6.5 hours daily. The mean time of work in a forced position (sitting) was on the level of 1.5 hours daily (traveling to the forest in an off-road vehicle), and office work - 1.6 hours. The selected forestry workers met the condition that the occupation of a forester was the only job performed by them since the beginning of their occupational career. Field studies were conducted during 2013-2015.

While traveling to the forest the forestry workers covered 1,699 kilometres monthly, by off road vehicles (previously by motorcycles) over uneven and bumpy terrain, which is translated to pain complaints reported by them while driving. A forester drives a considerable number of kilometers daily through the forest, and is exposed to many dangers, such as attack by animals, bite by vipers or ticks, or forest fire. According to the employees, for foresters to genuinely perform their task, they must be in a good state of health, have good vision and hearing, and condition for roaming (including 'strong legs'), as well as a good sense of direction, and possess good predispositions to perform this occupation.

The basic tasks of a forestry worker include [7]:

- protection of the forest against biological pest by installing nesting boxes for insects;

- boxes for bats, control of parasitic fungi, application of biocidal agents (autumn);

- selection of trees which to be felled (autumn): dead, ill or with defects;

- determination of the area of forest stands for the planned clearance at the end of the year, and surveillance over clearance, and exports of wood from the forest (winter);

- providing additional food for forest animals during periods of hard winter;

- exercising surveillance over planting of trees and participation in these activities (spring);

- maintenance of so-called anti-fire paths along the main transport roads and railway tracks (spring);

- controlling areas where new trees have been planted and carrying out tending activities in these areas (removal of weeds, mowing grass) (summer);

- planting new trees in the case of trees not having taken root, as well as performance of selective cuttings (summer);

- protection of forest against harm by humans and carrying out hunting economy (all year);

- activities related with the protection of young trees against deer (fencing of forest cultivation).

An active form of spending leisure time by foresters was declared by 79 (19\% of the total number of the foresters examined) - hunting 93 (22\%) - active walking, and 46 (11\%) - volleyball.
The control group were 119 office workers (administration, accountancy, supervision inspectors from individual forest districts), aged 23-64, mean age 45.8, and period of employment $1-45$ years, mean -21.0 years. They spent most of their working time in the office -7 hours on average, and the remaining time (1 hour daily) concerned work outdoors (mainly supervision inspectors). The mean time of work in a forced position (sitting) was 4.7 hours daily (mainly work with a computer).

The basic research instrument was a questionnaire designed by specialists, partially based on the standard Nordic questionnaire [8]. Seven areas of the motor system were selected for the study: the area of the neck, shoulders, upper part of the spine, hips, knees, feet, and lower back. The questions concerned, among other things, the occurrence of pain in foresters and in the control group, in a selected area of the motor system (or the lack of these complains), circumstances of the occurrence of pain, as well as reasons for the disappearance of this pain, as well as the total time of experiencing pain complaints during the entire period of employment. Questions were also asked about the cases of occurrence of injuries, job change caused by pain, or whether the forestry workers used medical advice. With respect to the lower part of the spine, the questions concerned the period of occurrence of pain (entire occupational life, last 12 months, or last 7 days), type of pain, events of disc prolapse, or potential hospital stay.

In order to assess the significance of the differences between the examined group of forestry workers and the control group, non-parametric chi-square test was applied. The $\mathrm{p}$ values $\mathrm{p}<0.05$ were considered statistically significant.

\section{RESULTS}

Pain complaints, injuries, and job change reported by forestry workers and the control group. The results of the survey showed that from among 7 areas of the motor system examined, the forestry workers most frequently reported pain complaints concerning the lower back $(65.7 \%$ of the total number of foresters in the study; 272 people), while in the control group, 55.5\% of respondents (66) mentioned pain complaints concerning this area. Pain complaints were significantly more often observed in foresters, compared to the control group ( $\mathrm{p}=0.041)$ (Fig. 1).

The area of the knees was placed on the second position, according to the frequency of reported complaints $(51.7 \%$ of the forestry workers examined, 214 persons), with the lower frequency of complaints noted in the control group

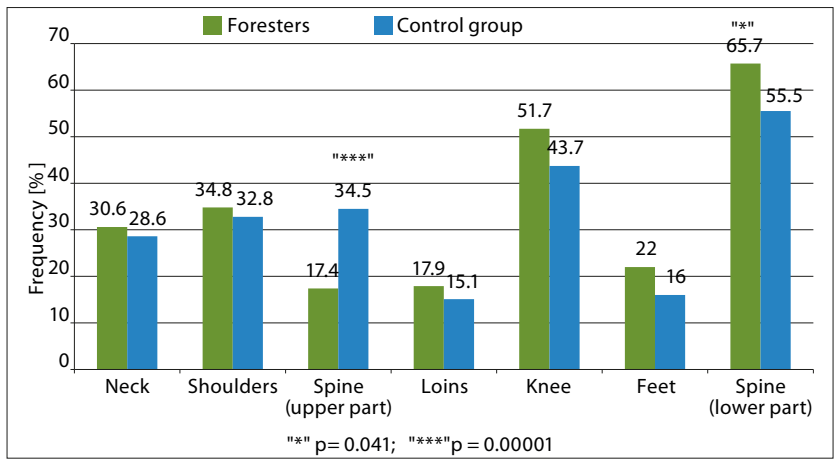

Figure 1. Frequency of reporting pain complaints in 7 regions of the motor system 
(43.7\%, 52 persons); however, the differences were statistically insignificant.

With respect to the subsequent areas of the motor system in forestry workers (neck, shoulders), the frequency of reported complaints was lower (30.6-34.8\%, respectively), while the lowest frequencies were noted with respect to the remaining 3 areas: upper part of the spine (17.4\%), hips (17.9\%), and feet $(22 \%)$. In the majority of above-analyzed cases, the registered frequencies of complaints among foresters were higher than the frequencies noted in the control group (differences were statistically insignificant). The exception was the area of the upper part of the spine, where higher data was obtained in the control group (34.5\%), compared to the group of forestry workers (17.4\%); the differences were very highly significant statistically ( $\mathrm{p}=0.00001)$.

Considering the number of injuries reported by forestry workers in 6 areas of the motor system, the largest number of these body injuries concerned the areas of the knees (53 cases; $12.8 \%$ of the total number of respondents). A smaller number of such events was noted in the areas of shoulders and feet (33 cases each; 8\%) and in the area of the neck (18; $4.3 \%)$ and hips $(9 ; 2.2 \%)$, while considerably less in the area of the upper part of the spine (4; 1\%) (Figs. 2 and 3). In the control group, a smaller number of injuries were observed, compared to the group of forestry workers (1-12 cases); the difference was highly significant $(p=0.00001)$.

Also, the most frequent cases of job change in relation with pain complaints concerned the area of the knees (46 cases;
$11 \%)$. A considerably smaller number of cases of job change pertained to the area of the hips ( 21 cases; $5 \%$ ), feet ( 20 cases; $5 \%$ ), neck (15 cases; $4 \%$ ), and the smallest - the area of the upper part of the spine ( 9 cases; $2 \%$ ). In the control group, the frequency of job changes was the lowest (differences were statistically insignificant).

Circumstances of occurrence of pain and reasons for disappearance of pain in the examined 6 areas of the motor system (neck, shoulders, upper part of the spine, hips, knees, feet). Analysis of the circumstances of the occurrence of pain (Tabs. 1 and 2) in the morning, during the workday, after performing hard work activities, in the evening during rest - showed that the forestry workers most frequently reported complaints in the area of the knees (23.4\%) during the workday (the difference in frequency was highly significant compared to the control group; $\mathrm{p}=0.0003$ ), and in the evening during rest $(\mathrm{p}=0.013)$. The subsequent positions were occupied by the area of the neck (11.8\%), shoulders (13.3\%), feet (9.7), hips (8.2), and the upper part of the spine (5.6) during the workday. With respect to the feet, the difference in the frequency, compared to the control group, was significantly higher statistically during the workday $(\mathrm{p}=0.012)$, and in the evening $(\mathrm{p}=0.002)$ (Figs. 2 and 3).

A low percentage of forestry workers reported the occurrence of pain every day, concerning the areas of the knees (8.9\%), neck (6), feet (4.8), and hips (3.6); with statistically significant differences observed for the areas

Table 1. Circumstances of pain occurrence and causes of pain disappearance in regions examined: neck, shoulders and upper spine

\begin{tabular}{|c|c|c|c|c|c|c|c|c|c|c|c|c|}
\hline \multirow{3}{*}{$\begin{array}{l}\text { Circumstances of occurence of pain } \\
\text { Pain disappearance }\end{array}$} & \multicolumn{4}{|c|}{ Neck } & \multicolumn{4}{|c|}{ Shoulders } & \multicolumn{4}{|c|}{ Upper part of the spine } \\
\hline & \multicolumn{2}{|c|}{ foresters } & \multicolumn{2}{|c|}{ control group } & \multicolumn{2}{|c|}{ foresters } & \multicolumn{2}{|c|}{ control group } & \multicolumn{2}{|c|}{ foresters } & \multicolumn{2}{|c|}{ control group } \\
\hline & $\mathrm{n}$ & $\%$ & $n$ & $\%$ & $n$ & $\%$ & $n$ & $\%$ & $n$ & $\%$ & $\mathrm{n}$ & $\%$ \\
\hline \multicolumn{13}{|l|}{ Occurence of pain } \\
\hline - in the morning & 17 & 4.1 & 5 & 4.2 & 26 & 6.3 & 2 & 1.7 & 9 & 2.2 & 0 & 0 \\
\hline - during the day & 49 & 11.8 & 20 & 16.9 & 55 & 13.3 & 21 & 17.6 & 23 & 5.6 & 18 & 15.1 \\
\hline -in the evening after rest & 12 & 2.9 & 0 & 0 & 21 & 4.1 & 3 & 2.5 & 9 & 2.2 & 3 & 2.5 \\
\hline - every day & 25 & 6.0 & 1 & 0.8 & 37 & 8.9 & 0 & 0 & 9 & 2.2 & 0 & 0 \\
\hline \multicolumn{13}{|l|}{ Pain disappearance } \\
\hline - after motion & 50 & 12.1 & 12 & 10.1 & 59 & 13.3 & 11 & 9.2 & 27 & 6.5 & 14 & 11.8 \\
\hline - after rest & 83 & 20 & 22 & 18.5 & 85 & 20.5 & 28 & 23.5 & $48^{*}$ & 11.6 & 27 & 22.7 \\
\hline
\end{tabular}

Table 2. Circumstances of pain occurrence and causes of pain disappearance in regions examined: loins, knee and feet

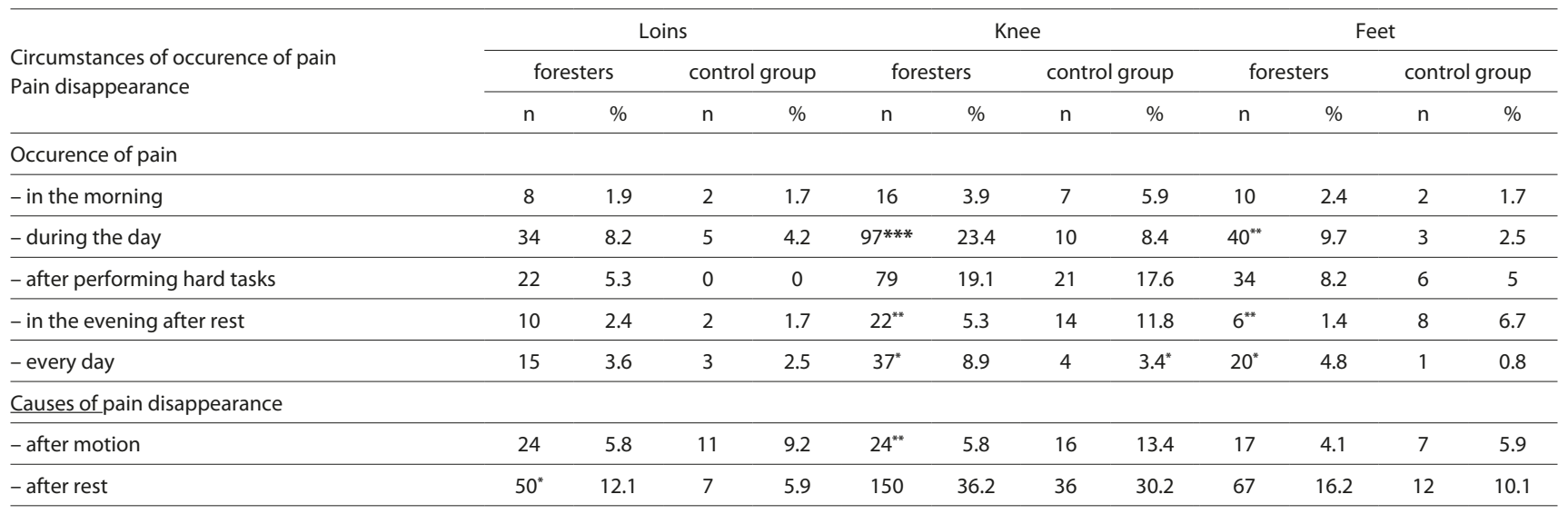

${ }^{*} \mathrm{p}<0.05 ;{ }^{* *} \mathrm{p}<0.01 ; * * \mathrm{*} p<0.001$ 


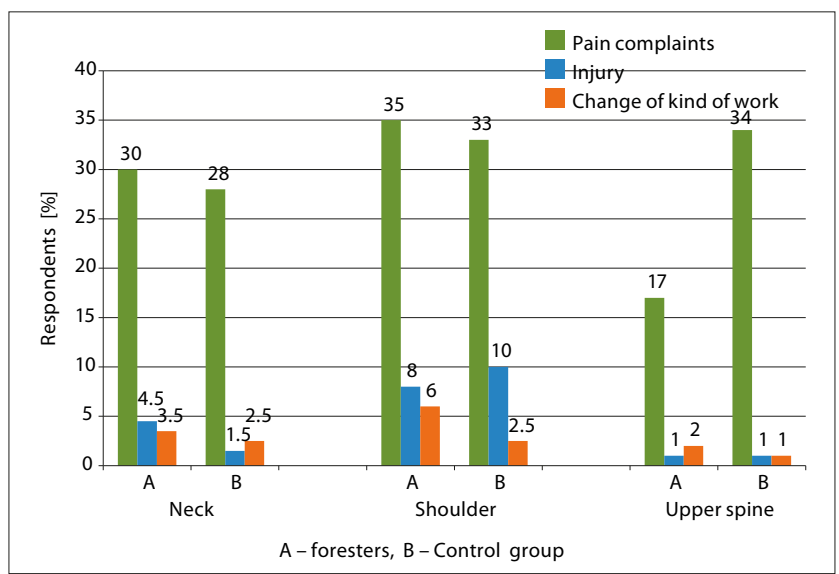

Figure 2. Pain complaints, injures and change of the kind of work, reported in 3 regions examined: neck, shoulders and upper spine

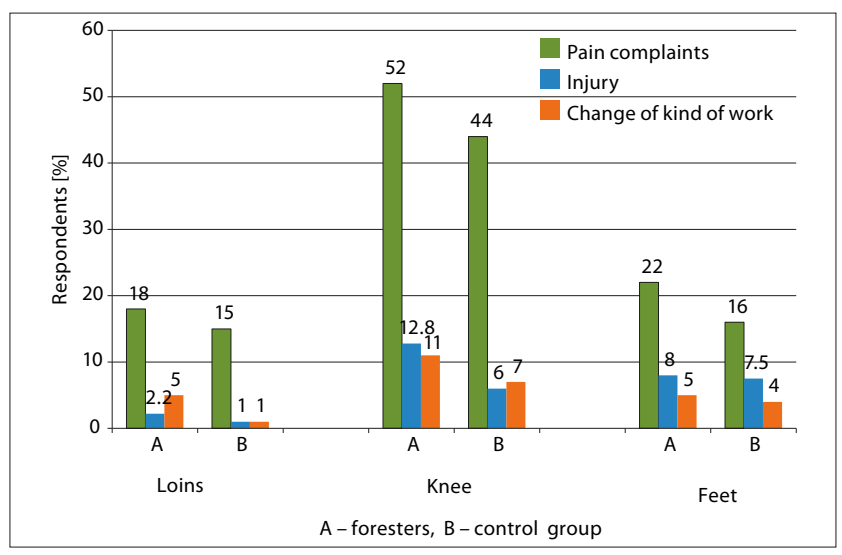

Figure 3. Pain complaints, injures and change of the kind of work, reported in 3 regions examined: loins, knee and feet

of the knees $(\mathrm{p}=0.044)$ and feet $(\mathrm{p}=0.049)$, compared to the control group.

The causes of disappearance of pain, according to the examined area of the motor system, were also analyzed. Pain most frequently disappeared in the area of the knees after rest (36.2\%); however, to a lesser extent, the disappearance of pain was reported with respect to the areas of the neck (20\%), shoulders (20.5), feet (16.2), hips (12.1), and the upper part of the spine (11.6). Statistically significant differences in the perception of the disappearance of pain (between foresters and control group) were noted concerning the hips $(12.1 \%$ vs. $5.9 \% ; \mathrm{p}=0.05)$, and the upper part of the spine (11.6 vs. 22.7; $\mathrm{p}=0.037)$. A considerable disappearance of pain after becoming mobile was noted concerning the knees $(5.8 \%$ vs. $13.4 ; \mathrm{p}=0.005)$, and the upper part of the spine $(6.5 \%$ vs. $11.8 \% ; \mathrm{p}=0.03)$.

Total duration of complaints in 6 areas of the motor system and use of medical advice. Analysis of the total duration of pain complaints among foresters according to 5 intervals of the period of employment, showed that with respect to the neck the most frequently reported pain concerned the interval $6-10$ years $(11.8 \%)$ and $2-5$ years $(10.6 \%)$ In the remaining intervals, the frequency of complaints was considerably lower (3.4\% after one year, and 5.8\% after $11-20$ years). In the control group, the frequency of pain was lower, and the differences between the groups were statistically insignificant (Figs. 4 and 5).

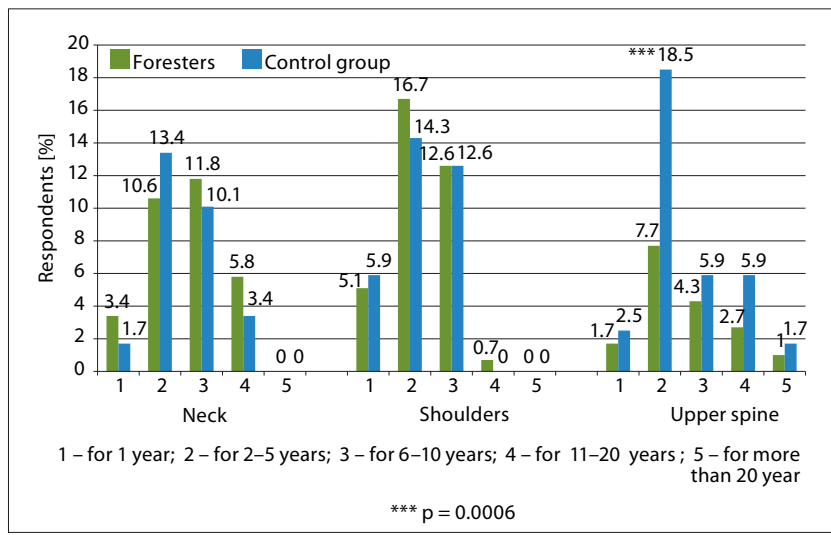

Figure 4. Total duration of pain complaints, reported in 3 regions examined: neck, shoulders and upper spine

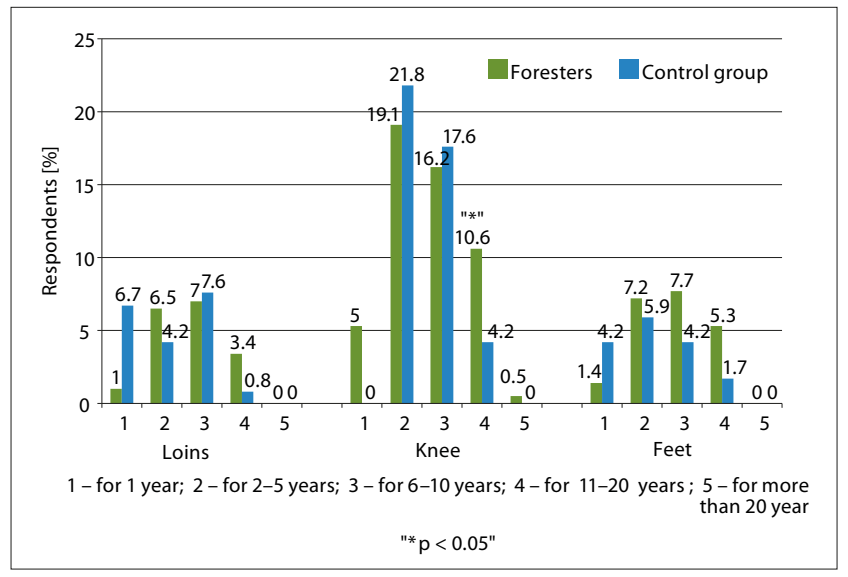

Figure 5. Total duration of pain complaints, reported in 3 regions examined: loins, knee and feet

A higher frequency of complaints was observed with respect to the shoulders for the pain interval lasting for $2-5$ years (16.7\%), and slightly lower for $6-10$ years (12.6\%). Slightly lower values were also obtained in the control group; however, the differences were statistically insignificant.

Considering the subsequent areas of the motor system, such as the upper part of the spine, shoulders and feet, the registered frequency of complaints in individual intervals of the period of employment were considerably lower, and reached from $6.5-7.7 \%$ for the period of lasting of pain: 2-10 years (differences statistically insignificant compared to the control group, except for the upper part of the spine, where the frequency in the control group was greater: $18.5 \%$ versus $7.7 \%$; $=0.0006$, within the interval of 2-5 years).

In turn, for the area of the knees, the frequency of complaints was decisively the highest (with respect to the above-analyzed areas) for the period of pain of 2-5 years (19.1\%), and 6-10 years (16.2\%). In most cases, these data are higher than the values obtained in the control group; however, they did not significantly differ statistically.

During the period of the last 12 months, medical advice was used by 49 forestry workers with neck pain (12\% of the total number of respondents with neck pain), 69 with shoulders pain (17\%), 28 with pain concerning the upper part of the spine (7\%), 30 with shoulder pain (7\%), 85 with knees pain (21\%), and 41 forestry workers with feet pain $(10 \%)$. 
Duration of occurrence of pain complaints, type of pain, disc prolapse, hospitalization, and job change - related with low back. Considering the lower part of the spine forestry workers informed about complaints which had occurred within the last 12 months (35\%; 145 persons), and to a smaller degree, during the last 7 days $(26.8 \%)$. For the period covering the entire occupational life (occurrence of complaints earlier than the last 12 months), the presence of pain complaints was declared by 16 forestry workers (3.9\%). In the control group, the frequency of pain complaints was usually lower - for the period of the last 7 days $-28.6 \%$ (34 persons), and the last 12 months $-26.9 \%$ (32 persons); nobody reported pain lasting for the entire occupational life. The differences between the groups examined were statistically insignificant (Fig. 6).

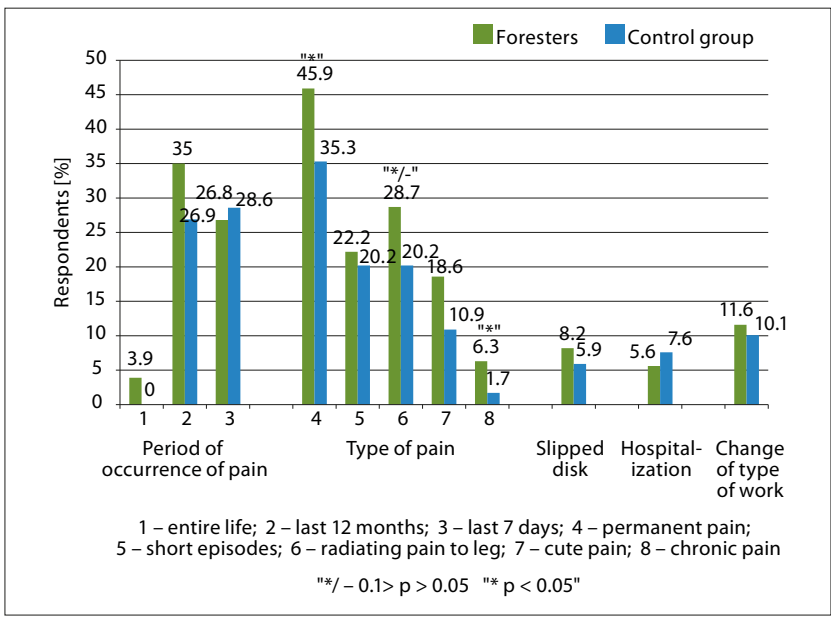

Figure 6. Period of occurrence pain complaints, type of pain, slipped disc, hospitalization, change of the kind of work associated with the lower part of the spine

Pain reported by forestry workers was usually of a permanent character (45.9\%; 190 respondents); considerably less pain was reported in the control group (35.3\%; 42 persons; the differences was significant; $\mathrm{p}=0.039)$. Pain radiating to the leg was reported less frequently $(28.7 \%$; differences was insignificant; $\mathrm{p}=0.06$ ), pain occurring in short episodes (22.2\%; 92 persons; differences insignificant), pain of an acute character (18.6\%; 77 persons; differences significant; $\mathrm{p}=0.049)$, and chronic pain $(6.3 \%, 26$ persons; differences significant; $\mathrm{p}=0.048)$.

Disc prolapse occurred in 34 forestry workers (8.2\%), while in the control group it concerned 7 persons (5.9\%). Due to back pain, 23 forestry workers (5.6\%) were hospitalized.

In association with pain complaints in the lower back, 48 forestry workers (11.6\%) had to change their job periodically, whereas in the control group this concerned 12 respondents (10.1\%); the differences was insignificant.

Circumstances of the occurrence of pain, causes of disappearance of pain in the lower back, and total duration of complaints. The performed analysis of the circumstances of the occurrence of pain in the lower back (in the morning, during the workday, after performing hard work activities, in the evening during rest) showed that the forestry workers most often reported complaints during the workday (28.3\%, 117 persons), and after performing hard work activities $(27.1 \%, 112$ persons). In the control group, the frequency of
Table 3. Circumstances of pain occurrence and causes of pain disappearance in region lower back ('* $\left.p<0.05^{\prime}\right)$

\begin{tabular}{lcccc}
\hline \multirow{2}{*}{$\begin{array}{l}\text { Circumstances of occurrence of pain } \\
\text { Pain disappearance }\end{array}$} & \multicolumn{5}{c}{ Lower back } \\
\cline { 2 - 5 } & $\mathrm{n}$ & $\%$ & $\mathrm{n}$ & $\%$ \\
\hline Occurrence of pain & & & & \\
\hline - in the morning & 21 & 5.1 & 5 & 4.2 \\
\hline - during the day & $117^{*}$ & 28.3 & 21 & 17.6 \\
\hline - after performing hard tasks & 112 & 27.1 & 32 & 26.9 \\
\hline - in the evening after rest & 22 & 5.3 & 8 & 6.7 \\
\hline - every day & 48 & 11.6 & 7 & 5.9 \\
\hline Causes of pain disappearance & & & & \\
\hline - after motion & 83 & 20 & 21 & 17.6 \\
\hline - after rest & 187 & 45.2 & 45 & 37.8 \\
\hline
\end{tabular}

these complaints was considerably lower, during the workday (17.6\%, 21 persons); the differences was significant $(\mathrm{p}=0.019)$. A relatively large group of forestry workers mentioned the occurrence of pain complaints every day $(11.6 \%, 52$ respondents), while in the control group - only 7 persons (5.9\%); the differences was insignificance $(p=0.07)$. The forestry workers in the study most often reported the disappearance of pain after rest (45.2\%; 187 persons), slightly less in the control group (37.8\%; 45 persons); the differences was insignificant (Tab. 3).

Pain complaints in the lower back most frequently reported by forestry workers covered 2 intervals of the total duration of pain for the period of $6-10$ years $(23.7 \%, 98$ persons) and $11-20$ years (19.3\%; 80 persons), and slightly less frequently for the period of $2-5$ years $(17.4 \% ; 72$ persons), while the least frequent - for the period shorter than 1 year $(3.4 \%$; 14 persons), and the period longer than 20 years $(1.9 \%, 8$ persons). In the control group, pain complaints were reported less often; the differences were statistically insignificant (Fig. 7).

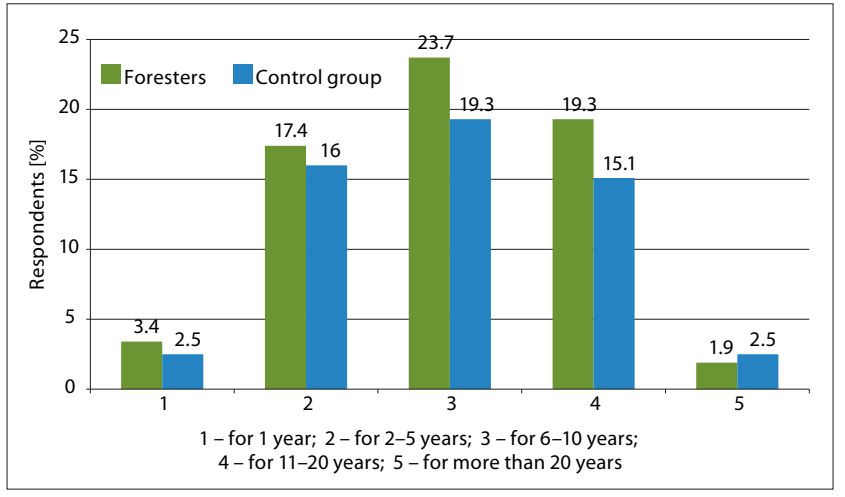

Figure 7. Total duration of pain complaints in the lower part of the spine

Within the period of the last 12 months, due to pain complaints concerning the lower back, 117 forestry workers ( $28 \%$ of the total number of forestry workers with low back pain) used medical advice. 


\section{DISCUSSION}

The presented analysis of the results obtained clearly shows that pain complaints considerably more often occurred in the study group (forestry workers), compared to the control group; this especially concerned the lower back area and the knees. Serious health consequences were observed, such as disc prolapse, frequent hospitalizations, an increased number of injuries concerning the knees, as well as an enforced decision of job change.

Analysis of the frequency of occurrence of symptoms on the part of the musculoskeletal system performed by Gallis [5] among Greek forestry workers confirmed that in the period of the last 12 months, $87.2 \%$ of the total number of respondents (total 78 persons) complained of pain and discomfort in the lower back, and $61.5 \%$ in the area of the knees. These data are considerably higher than those obtained in the presented study and the study by Ponten [6]. This is probably due to the fact that the group of Greek forestry workers considerably differed from Polish forestry workers. The group of Greek forestry workers included lumberjacks who felled trees, were exposed to high physical loads, static bending or twisting of the spine, and the effect of mechanical vibration on the hands; hence, the observed high frequency of pain complaints in the group of Greek forestry workers in the area of hands/wrists (74.3\% of the total number of respondents).

As many as $17.9 \%$ of the total number of Greek forestry workers were hospitalized at least once during their professional career due to back pain, and $42.3 \%$ of them had used medical advice within the period of the last 12 months, whereas in the case of Polish forestry workers, $5.6 \%$ of the total number of respondents were treated in a hospital and used medical advice $-28 \%$ persons, during the period of the last 12 months. 33 Greek forestry workers (42.3\% of the total number) could not normally perform their occupational activity due to the problems with the knees. In the case of Polish forestry workers, the highest frequency of job change (11.19\%; 46 forestry) was noted due to pain in the area of the knees.

In their study Hagen and Magnus [9] analyzed the frequency of occurrence of disorders concerning the neck/shoulders and low back, and showed their relationship with the tasks performed at work and perception of psychosocial stress. Low back disorders were more frequently observed among physical workers than administration employees [odds ratio $(\mathrm{OR})=1.98$ ]. The frequency of occurrence of disorders of the neck/shoulders was significantly higher among operators of machinery $(\mathrm{OR}=3.37)$ and physical workers $(\mathrm{OR}=2.34)$, compared to administration employees.

The study conducted by Gandaseca and Yoshimura [10] demonstrated that many forestry workers complain of low back pain. In addition, these researchers confirmed a great physical effort, especially while lifting heavy objects, such as power saws or logs, and that work in forestry was assessed as heavy, dirty and dangerous, and often related with forced, improper posture at work, as well as exposure to noise and vibration. The study conducted by the Forestry and Wood Industries Committee [11] indicated that among operators of power saws aged 35-54, musculoskeletal disorders most frequently occur in the lumbosacral region (45\%) and the neck/shoulder region (37\%).

Bovenzi [12] observed an elevated risk of injuries to the upper limbs among forestry workers operating power saws, compared to the control group. It was found that the indicators of persistent pain in the upper extremities, inflammation of the tendons and muscles, and carpal tunnel syndrome were significantly higher among forestry workers than in the control group. Calvo [13] found that among forestry workers the occurrence of musculoskeletal disorders (MSD) was manifested by disorders in the function of the neck and upper extremities.

The performance of repeated work activities by forestry workers, often in twisted and bent backwards positions, lifting and carrying of heavy loads, and whole body vibration, may cause considerable pain complaints, especially in the area of lower back. Studies conducted by Grzywiński [14, 15, 16], concerning cultivation and tending activities in the area of forest protection in Poland, confirmed the fact of the occurrence of high dynamic work load in forestry workers. The highest values of energy expenditure were obtained by Grzywiński during the planting of pine tree saplings $(8.6 \mathrm{MJ} / 8 \mathrm{~h})$, using a manual dibber; manual weeding with a scythe, and early cleaning with a club in a young forest (10.1-11.4 MJ/8h), and while performing activities related with the protection of young trees (fencing and digging holes $(9.8 \mathrm{MJ} / 8 \mathrm{~h}$ ).

An additional factor loading the lower part the spine is driving in an off-road vehicle over uneven pathways in the forest, resulting in the emission of mechanical vibration on high levels, and shocks exerting a hazardous effect on the skeletal system.

Intensive pain reported by forestry workers in the knees may be explained by the character of work involving, to a large extent, the lower extremities, consisting in walking long distances over an uneven area in the forest in various seasons of the year.

A significantly higher frequency of pain in the area of the upper part of the spine in the control group, compared to the forestry workers, may be explained by their performance of office activities in a forced sitting position for a long uninterrupted period of time (approximately 5 hours daily).

\section{CONCLUSIONS}

1. The survey showed that among 7 analyzed areas of the motor organ, forestry workers most often reported lower back pain (272 persons, $65.7 \%$ of the total number of forestry workers examined; 66 persons, $55.5 \%$ in the control group). The differences between these groups were statistically significant $(\mathrm{p}=0.04)$.

2. The area of the knees occupied the second position according to the frequency of reporting pain (214 forestry workers, $51.7 \%$; 52 persons, $43.7 \%$ in the control group); the differences were statistically insignificant.

3. Forestry workers most often evaluated pain occurring in the lower part of the spine as permanent (45.9\%), radiating to the leg $(28.7 \%)$, and as an acute pain $(18,6 \%)$; in the control group mainly permanent pain was reported (35.3\%).

4. The performance by forestry workers of repeated work activities in unfavourable body positions, lifting and carrying heavy loads, and exposure to whole body vibration seem to be the main cause of the development of pain complaints and disc prolapse in the lower back.

5. Pain and injuries in the area of the knees may be due to the character of the work performed (walking long distances through the forest). 


\section{REFERENCES}

1. Schneider E, Irastorza X. OSH in figures: Work-related musculoskeletal disorders in the EU - Facts and figures. European Agency for Safety and Health at Work. European Risk Observatory Report. Luxembourg, 2010.

2. EODS - European Occupational Disease Statistics. European Occupational Disease Statistics. Available at: http://epp.eurostat ec.europa.eu/portal/page/portal/health/health_safety_work/data/ database. [access:30 March 2016]

3. Occupational Diseases. Statistics on Occupational Diseases. 2014 http://www.occupationaldiseases.nl/content/statistics-occupationaldiseases-2014). [access: 12 August 2015].

4. ESWC - European Survey on Working Conditions. Available at: http:// www.eurofound.europa.eu/ewco/surveys/ index.htm. [cytowany 30 marca 2016].

5. Gallis Ch. Work-related prevalence of musculoskeletal symptoms among Greek forest workers. Int J Ind Ergon. 2006; 36:731-736.

6. Pontén B. Health risks in forest work-a program for action. Report No. 177, Dept. of Operational Efficiency, College of Forestry, Garpenberg, Sweden, 1988

7. Rozmowa Władysława Kusiaka z Zygmuntem Sadowskim. [access: 30 March 2015].http://www.przegladlesniczy.com.pl/rozmowa_sadowski. html

8. Kuorinka I, Jonsson B, Kilbom A, Vinterberg H, Biering-Sørensen F, Andersson G, et al. Standardised Nordic questionnaires for the analysis of musculoskeletal symptoms. Appl Ergon. 1987; 18(3): 233-237.
9. Hagen K, Magnus P, Vetlesen K. Neck/shoulder and low-back disorders in the forestry industry: relationship to work tasks and perceived psychosocial job stress. Ergonomics. 1998; 41(10): 1510-8.

10. Seca Gandaseca \& Tetsuhiko Yoshimura, Occupational Safety, Health and Living Conditions of Forestry Workers in Indonesia. J Forest Res. 2001; 6 (4): 281-285.

11. Occupational safety and health in forestry. Forestry and Wood Industries Committee. Second Session. Geneva, 1991.

12. Bovenzi M, Zadini A, Franzinelli A, Bargogni F. Occupational musculoskeletal disorders in the neck and upper limbs of forestry workers exposed to hand-arm vibration. Ergonomics. 1991; 34(5): 547-62.

13. Calvo A. Musculoskeletal disorders (MSD) risks in forestry: a case study to propose an analysis method. International Conference: September 15-17, 2008 Ragusa - Italy. "Innovation Technology to Empower Safety, Health and Welfare in Agriculture and Agro-food Systems"

14. Giefing D, Grzywiński W, Kosak J. Physical work load of workers during planting using different types of dibbles. Electronic J Polish Agricl Univer. Forestry. 2003; 6(1): 7

15. Grzywiński W. Energy expenditure in some silvicultural works. Electronic J Polish Agric Univer Forestry. 2009; 12(1): 20.

16. Grzywiński W, Turowski R. Obciążenie praca podczas wykonywania czynności z zakresu ochrony lasu. Poznańskie Towarzystwo Przyjaciół Nauk. Wydział Nauk Rolniczych i Leśnych. Prace Komisji Nauk Rolniczych i Komisji Nauk Leśnych. 2012; 103:79-85. 